\title{
Commentary: Looking for support for the MitraClip
}

\author{
Abe DeAnda, Jr, MD, ${ }^{a}$ and Syed A. Gilani, $\mathrm{MD}^{\mathrm{b}}$
}

\author{
From the Divisions of ${ }^{\mathrm{a} C a r d i o v a s c u l a r}$ and Thoracic Surgery and ${ }^{\mathrm{b}}$ Cardiology, University of Texas Medical \\ Branch-Galveston, Galveston, Tex. \\ Disclosures: Authors have nothing to disclose with regard to commercial support. \\ Received for publication Jan 24, 2019; accepted for publication Jan 24, 2019; available ahead of print Feb 21, \\ 2019. \\ Address for reprints: Abe DeAnda, Jr, MD, Division of Cardiothoracic Surgery, UTMB-Galveston, 301 Univer- \\ sity Blvd, Galveston, TX 77551 (E-mail: abdeanda@utmb.edu). \\ J Thorac Cardiovasc Surg 2019;158:95-6 \\ 0022-5223/ $\$ 36.00$ \\ Copyright $(C) 2019$ by The American Association for Thoracic Surgery \\ https://doi.org/10.1016/j.jtcvs.2019.01.094
}

Treatment options for degenerative mitral regurgitation have evolved from medical management to valve replacement to mitral valve repair, with each step of the way associated with improvement in patient outcomes. ${ }^{1}$ In 1991, Alfieri's group ${ }^{2}$ began repairing the mitral valve with a novel edge-to-edge technique. Their description of 35 (out of 299) repairs in which they used this technique had early positive results, especially when the prolapsing leaflet was the anterior leaflet and an annuloplasty ring was used. ${ }^{2}$ Increasing experience suggested an expanded role for this technique, such as bileaflet prolapse (Barlow syndrome) and in the setting of significant posterior annular calcification. ${ }^{3}$ This surgical technique seemed ripe for translation into a percutaneous approach, with the caveat that a transcatheter technique of stabilizing the annulus in conjunction with the mitral repair would make sense. ${ }^{4}$

The MitraClip System (Abbott Vascular, Santa Clara, Calif) is one such platform for transcatheter edge-to-edge repair in the management of high-risk or inoperable patients with symptomatic degenerative mitral regurgitation. The EVEREST II (Endovascular Valve Edge-to-Edge Repair Study) trial compared MitraClip versus conventional mitral valve surgery and found a significant need for surgery for mitral valve dysfunction in the MitraClip arm at 1 year $(20.4 \%$ vs $2.2 \% ; P<.001){ }^{5}$ Another review of the EVEREST II data suggested that anterior leaflet pathology was strongly associated with the subsequent need for mitral valve replacement after the index procedure, ${ }^{6}$ a finding seemingly at odds with the earlier observation of the Alfieri group. ${ }^{2}$ Nevertheless, the Milan group clearly showed an advantage of MitraClip in high-risk or elderly patients, with low operative mortality $(2 \%)$, freedom from mitral regurgitation of at least $3+$ of $80 \% \pm 7 \%$ at 1 year, and significant improvements in quality of life and 6-minute walk test performance. ${ }^{7}$ Expanding the clinical indications for MitraClip includes considering functional $\mathrm{MR}^{8}$ and lowering the risk profile of patients considered. ${ }^{9}$ The former is being addressed by the Cardiovascular Outcomes Assessment of the MitraClip Percutaneous Therapy for Heart

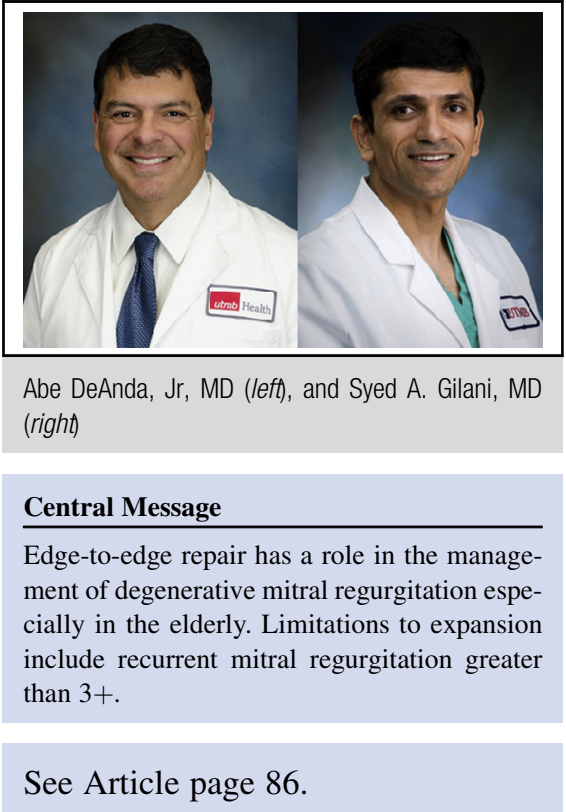

Failure Patients with Functional Mitral Regurgitation (COAPT) trial.

In this issue of the Journal, Buzzatti and colleagues ${ }^{9}$ address the latter. In considering elderly patients outside the high-risk or inoperable group (Society of Thoracic Surgeons predicted risk of mortality $<8 \%$ ), they find that in the first year after the index procedure, patients receiving MitraClip have a benefit in survival, but this benefit has disappeared by the 5-year mark. A significant contribution to the long-term outcomes is the presence of recurrent MR of at least 3+ in MitraClip patients relative to surgical patients. In this study, the 5-year estimate for MR of at least $3+$ was $36.9 \%$ for MitraClip, compared with $3.9 \%$ in the surgical arm. ${ }^{9}$ This compares with the rates of $12.3 \%$ and $1.8 \%$ seen in EVEREST $\mathrm{II},{ }^{10}$ with the caveat that the EVEREST II patients were younger. Nevertheless, for the elderly patient at low or moderate risk, the 1-year results may be sufficient to advocate for the transcatheter approach. What would not be prudent at this time would be to suggest expansion of the technology to the younger low- to moderate-risk cohort. At least not until the original bug in the system is addressed: How do you support the annulus when performing a transcatheter edge-to-edge repair? Until this is accomplished, recurrent $\mathrm{MR}$ of at least $3+$ will continue to be a problem. 


\section{References}

1. Carpentier A. Cardiac valve surgery - the "French correction." J Thorac Cardiovasc Surg. 1983;86:323-37.

2. Fucci C, Sandrelli L, Pardini A, Torracca L, Ferrari M, Alfieri O. Improved results with mitral valve repair using new surgical techniques. Eur J Cardiothorac Surg. 1995;9:621-6; discussion 626-7.

3. Alfieri O, Maisano F, De Bonis M, Stefano PL, Torracca L, Oppizzi M, et al. The double-orifice technique in mitral valve repair: a simple solution for complex problems. J Thorac Cardiovasc Surg. 2001;122:674-81.

4. Alfieri O, Denti P. Alfieri stitch and its impact on mitral clip. Eur J Cardiothorac Surg. 2011;39:807-8.

5. Mauri L, Foster E, Glower DD, Apruzzese P, Massaro JM, Herrmann HC, et al; EVEREST II Investigators. 4-year results of a randomized controlled trial of percutaneous repair versus surgery for mitral regurgitation. J Am Coll Cardiol. 2013;62:317-28.

6. Glower D, Ailawadi G, Argenziano M, Mack M, Trento A, Wang A, et al; EVEREST II Investigators. EVEREST II randomized clinical trial: predictors of mitral valve replacement in de novo surgery or after the
MitraClip procedure. J Thorac Cardiovasc Surg. 2012;143(4 Suppl): S60-3.

7. Taramasso M, Maisano F, Denti P, Latib A, La Canna G, Colombo A, et al. Percutaneous edge-to-edge repair in high-risk and elderly patients with degenerative mitral regurgitation: midterm outcomes in a single-center experience. $J$ Thorac Cardiovasc Surg. 2014;148:2743-50.

8. AATS Ischemic Mitral Regurgitation Consensus Guidelines Writing Committee, Kron IL, LaPar DJ, Acker MA, Adams DH, Ailawadi G, Bolling SF, et al. 2016 update to The American Association for Thoracic Surgery (AATS) consensus guidelines: ischemic mitral valve regurgitation. J Thorac Cardiovasc Surg. 2017; 153:e97-114.

9. Buzzatti N, Van Hemelrijck M, Denti P, Ruggeri S, Schiavi D, Scarfò IS, et al. Transcatheter or surgical repair for degenerative mitral regurgitation in the elderly: a propensity weighted analysis. J Thorac Cardiovasc Surg. 2019;158: 86-94.e1.

10. Feldman T, Kar S, Elmariah S, Smart SC, Trento A, Siegel RJ, et al; EVEREST II Investigators. Randomized comparison of percutaneous repair and surgery for mitral regurgitation: 5-year results of EVEREST II. J Am Coll Cardiol. 2015;25:2844-54. 